\title{
Atividade sagrada pelo Método da Escavação
}

\author{
Eliana Anjos Furtado ${ }^{a}$, Juliana Leitáo Marcondes ${ }^{b}$ \\ ${ }^{a}$ Terapeuta ocupacional, Doutora em Educação, Porto Alegre, RS, Brasil

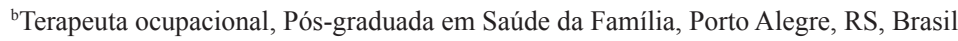

\begin{abstract}
Resumo: A escavação é uma metodologia clínica e de ensino criada pela primeira autora que constitui-se em uma maneira de ajudar o sujeito a pensar, fazer e falar. Acontece pela escavação do fazer, como uma desocultação e/ou um desvelamento em busca da compreensão de sua atividade sagrada. Pela escavação, os sujeitos passam a compreender o pensamento, os valores e a própria sociedade em que vivem no momento em que escavam a sua história de vida e suas relações com o fazer, incluindo atividades cotidianas, de socialização e de trabalho. Utilizamos uma análise reflexiva para abordarmos o papel da escavação e o conceito de atividade sagrada. Parte-se da atividade sagrada como essência de todo ser humano, que não necessariamente é a atividade que desempenhamos no cotidiano ou na vida de trabalho. É aquela em que o sujeito vai estar nela e vai vivê-la por inteiro, genuinamente, sem mascaramentos; é a entrega do sujeito para a atividade, para o outro, para com ele mesmo e nele mesmo, através do ato de se perguntar. A busca da atividade sagrada, portanto, é um processo de se perguntar, escavando as ações que o sujeito desenvolve cotidianamente, observando e percebendo o conteúdo dessa escavação e realocando espaços de acomodação para o que for sendo desvelado e com isso sacralizando o feito. Concluímos que, através do Método da Escavação, a ação sacralizadora do feito deverá permitir ao sujeito relacionar-se com amorosidade e, portanto, curar-se.
\end{abstract}

Palavras-chave: Atividade, Métodos, Terapêutica, Ensino, Terapia Ocupacional.

\section{Sacred activity by the Method of Excavation}

\begin{abstract}
Excavation is a clinical and teaching methodology created by the first author of this article. It constitutes a way of helping subjects think, make and speak. This process occurs through the excavation of making, unblinding and/or unveiling elements in search for the understanding of sacred activity. Through excavation, subjects understand their thoughts, values and the society in which they live in as they excavate their life stories and their relations with making, including their daily, social and work activities. We applied a thoughtful analysis to approach the role of excavation and the concept of sacred activity. Sacred activity is the core activity of every human being, which is not necessarily the activity we perform in our everyday or work life. Sacred activity is that in which subjects are inserted and experience integrally, genuinely and with no masking. Through sacred activities, subjects surrender, not only to the activity itself, but also to the other, to himself and into himself, by quest. Seeking sacred activity is, therefore, a process of questioning, excavating the routine of subjects, watching and understanding the content of this excavation, replacing and adjusting what is being unveiled, and thus making this activity sacred. In this analysis, we concluded that, by the method of excavation, the sacralization of this action should allow subjects to have tender relationships, and thus be cured.
\end{abstract}

Keywords: Activity, Methods, Therapeutics, Teaching, Occupational Therapy.

Autor para correspondência: Eliana Anjos Furtado, Rua Jaime Telles, 133, apto. 503, CEP 90460-030, Porto Alegre, RS, Brasil,

e-mail: efurtado@portoweb.com.br

Recebido em 12/8/2013; Revisão em 30/9/2013; Aceito em 4/10/2013. 


\section{Um olhar sobre a atividade humana através do Método da Escavação}

Se concordarmos que a atividade humana é a essência do ser humano e que é por meio dela que o homem se cria e se recria, ampliar esse entendimento e colaborar com o crescimento de áreas do conhecimento que discutam e pesquisem nesse sentido é tarefa da formação. O sentido da vida humana está na sua práxis, no seu fazer. Essa compreensão advém do simples fato de que a vida humana constitui-se, em uma de suas dimensóes, em um continuum de atividades e em um continuum experiencial onde se produz verdades (QUARENTEI, 2001).

É na atividade de trabalho que o homem produz sua história enquanto produtor de si. É no fazer humano que o homem se insere e produz subjetividades. Entendendo subjetividade, segundo Canguilhem (2006), como uma insatisfação sem interioridade e, ainda, na perspectiva, segundo Ricouer, de

[...] perda da origem soberana da mesma (subjetividade), recuperando-a em um papel mais modesto imposto pela necessidade de desapropriar-se de si mesmo na ação. (RICOUER, 1990 apud CLOT, 2006, p. 174).

Nesse sentido podemos explicar a disponibilidade humana em permitir-se desenvolver ações altruístas.

Vivemos em nossa sociedade uma crise de valores éticos e morais em que o poder de compra é o que governa a maioria das nossas açóes. Portanto, o governo de si está diretamente vinculado ao que posso pagar para adquirir algo. A noção de pertencimento está vinculada, prioritariamente, a adquirir coisas. As pequenas coisas do nosso cotidiano, tais como cumprimentar um vizinho, realizar pequenos favores ou socorrer alguém podem nos custar muito caro. O papel do ser autônomo hoje está diretamente vinculado a quanto se pode pagar por essa autonomia. Então, há, aqui, uma distorção no ser autônomo, pois a liberdade em "Ser" foi substituída por "Poder Ser" a partir "De".

Resgatar a autonomia é fazer com que o desejo em ser aflore em nós, a partir da força da luta interna. Precisamos usar da força para alcançarmos a autonomia, estabelecendo, com isso, uma relação de recaptare. A palavra resgate, pelo dicionário, origina-se de duas outras palavras em latim: recaptare e reexcaptare, que querem dizer "[...] retomar, recuperar, salvar, obter algo a custa de sacrifício, expiar" (FERREIRA, 1986, p. 1493).

Tendo essa compreensão, a formação do terapeuta ocupacional sempre esteve muito próxima desses princípios do fazer humano em que as atividades cotidianas e de trabalho são fatores preponderantes e, portanto, devem ser olhadas quase que microscopicamente, compreendidas em todas as suas dimensóes em um continuum e rigoroso exercício no que diz respeito a refletir e escrever sobre o entendimento que se tem dessas atividades no campo do conhecimento profissional e na nossa vida cotidiana. Dessa forma, Medeiros (2003) complementa que:

[...] a terapia ocupacional, como área de conhecimento e prática de saúde, interessa-se pelos problemas do homem em sua vida de atividades. [...] considera as atividades humanas como o produto e o meio de construção do próprio homem e busca entender a relação que esse homem, em atividade, estabelece em sua condição de vida e saúde (MEDEIROS, 2003, p. 27).

Portanto, a atividade de trabalho e a atividade de formação estão intrinsecamente ligadas e, para refletirmos sobre a relação estabelecida entre ambas, utilizaremos o conceito de trabalho de Schwartz (1996, p. 151 apud CUNHA, 2008, p. 11): "Atividade que associa inextricavelmente o antropológico, o histórico, heranças imemoriais e relaçóes sociais extremamente carregadas de sentido". Ainda, segundo o autor, a atividade de trabalho é atravessada de histórias, que, para Freire (2005), são o que nos fabrica através dos saberes científicos com possibilidades de produzir tais saberes por meio da experiência que vivenciamos nos processos históricos.

Para nós, terapeutas ocupacionais, o analisar e o aprofundar nosso conhecimento sobre a atividade de trabalho nos possibilita compreender as demais atividades, pois essa ficou, na história da humanidade, a atividade mais significativa do homem. De acordo com Foucault (1988), o trabalho como ato, atividade, possui três funçóes: produtiva, simbólica e função de adestramento ou disciplinar. Ainda, segundo o autor, o homem trabalha pela necessidade de criar, inventar antecipadamente o mundo em que vai viver. Essa antecipação ele chama de " fé na verdade" e diz que ela leva o indivíduo a desejar fixar relaçóes que tenham sempre um grau e uma força para transformarem-se em luta diária. Luta diária em que qualquer impedimento para realizá-la é fator de estresse, desconforto, crises, diminuição da autoestima, da estima etc. 
Schwartz (2003), em seu artigo intitulado Trabalho e saber, questiona se estamos satisfeitos com as instituiçóes do saber tal como elas funcionam. $\mathrm{O}$ autor nos diz que os critérios sobre o funcionamento das instituiçóes e a forma como articulam os conceitos, não levando em consideração o requestionamento dos saberes, eliminando o papel do debate de normas na dinâmica da produção de saberes, levam-nos a um distanciamento das atividades industriosas, entre a atividade de trabalho e a atividade de formaçáo. Schwartz (2004) define atividade industriosa como:

[...] atividade orientada por um objetivo. Com sua [...] solicitação inesgotável de se pensar [...] esta continuidade em nós, indo da instrumentação enigmática do corpo próprio ao confronto no campo da cultura, dos valores e das contradições - através do uso industrioso de si [...] (Schwartz, 2004, p. 23).

Enquanto terapeutas ocupacionais, perguntamo-nos se quando estamos debatendo as atividades como potência terapêutica agregamos as atividades industriosas em nossa análise? Josso (2004) diz que a qualidade do sujeito em formação está na sua capacidade de integrar todas as dimensôes do seu ser, que para a autora são:

O conhecimento de seus atributos de ser psicossomático e de saber-fazer consigo mesmo; o conhecimento das suas competências instrumentais e relacionais e de saber-fazer com elas; o conhecimento das suas competências de compreensão, de explicação e do saber-pensar. (JOSSO, 2004, p. 46)

Justificamos que o papel da escavação como um método clínico e de formação para os terapeutas ocupacionais possibilita uma forma de pensar a atividade humana em sua dimensão existencial, ética e estética a partir de um feito sacralizado e compreendido como tal.

\section{A indicação de uma atividade pelo método}

A escavação é uma maneira de ajudar o sujeito a pensar, fazer e falar. Esse processo acontece pela escavação do fazer, como uma desocultação e/ou um desvelamento. Pela escavação, os sujeitos passariam a compreender o pensamento, os valores e a própria sociedade em que vivem no momento em que escavam a sua história de vida e de suas relaçóes com o fazer, incluindo desde as atividades cotidianas, de socialização, até as atividades de trabalho.
$\mathrm{Na}$ escavação, na medida em que o sujeito vai respondendo e dando lugar ao que diz e ao que faz, existe um Eu que não é só reflexivo, mas sim um Eu imerso em uma determinada situação, um Eu que é corpo, que é percepção, que é sistema de ações e atos pelas manifestaçōes dos valores, do agir em si e do próprio efeito dos atos. Portanto, nessa relação oportunizada pela escavação, há uma imbricação do Eu na situação, tanto na prática terapêutica como no ensino, ou seja, há o domínio de uma atividade engajada no mundo. Esse engajamento e esse domínio é que vão dar poder ao sujeito, levando-o à sacralizaçáo do feito através do empoderamento que o processo escavatório possibilitará.

Entretanto, no campo específico da ação do terapeuta ocupacional e, consequentemente, na formação do aluno de Terapia Ocupacional, revisitar o corpo significa também olhar para aquele corpo que não se enquadra no padrão de um corpo ajustado e aceito socialmente e, sim, para um corpo sujeitado e sequelado e, portanto, pensar e repensar como esse sujeito irá enfrentar essa nova maneira de estar no mundo, em um mundo que exige um estereótipo de corpo perfeito, potencialmente, com capacidade de responder a qualquer demanda. Ao pensar em um corpo sequelado, há uma dupla condição a ser exercitada por esse sujeito: a primeira é a da própria sujeição enquanto condição do humano, estabelecendo-se e sendo estabelecida pelas relaçóes de poder e enfrentamentos; a segunda é a limitação para exercer o poder e os enfrentamentos, tendo que lidar com todos os empecilhos, desde os de falta de acesso à valorização pessoal, além do estranhamento que a limitação física e mental por si só já condicionam.

De acordo com Sant'Anna (1995), corpo é uma palavra polissêmica, uma realidade multifacetada e, sobretudo, um objeto histórico que, igualmente à língua, cada sociedade tem o seu próprio. O corpo, para essa autora, é, ainda, um processo, um objeto heterogêneo e plural, um resultado provisório entre técnica e sociedade, sentimentos e objetos, e que pertence menos à natureza do que à história.

Quando falamos em corpo-processo, trazemos um exemplo ligado à nossa prática clínica, em que, ao estabelecermos procedimentos avaliativos a respeito de uma incapacidade do sujeito em realizar uma determinada atividade, deparamos com a necessidade de entendermos quem é esse sujeito, como se constituiu enquanto ser ocupacional, que atividades realizou ao longo da sua trajetória de vida, como a entendeu, a que cultura pertence, qual o sentido dessa atividade para ele, como produz etc. Porque é dessa forma que buscamos, na Terapia Ocupacional, compreender as limitaçóes desse 
corpo ao realizar o movimento, ao executar uma tarefa, ao se expressar, olhar, perceber, sentir esse corpo a partir do oculto, do visível e do invisível, ou mesmo pela ausência de uma zona inexistente ou não mais existente.

Na proposta do Método da Escavação, as atividades realizadas são permeadas pelo questionamento do vivido no aqui e no agora da experiência e pelas memórias e percepçôes que essa experiência e a escavação promovem. Para o sujeito, ao realizar as atividades (experiência e o saber como experiência), o terapeuta ocupacional indica, com questôes, o que percebeu do processo e qual o impacto dessa percepção para o sujeito, checando-a (FURTADO, 2010).

Ao fazer isso, o terapeuta ensina o sujeito a se perguntar e, ao mesmo tempo, ensina a desvelar o campo perceptivo da experiência dele, produzindo um novo olhar da experiência vivida. Isso tudo dá novos agenciamentos e dispositivos de saber, potencializando intervenção terapêutica ocupacional e criando novas demandas de investigação por meio de novas experiências e ampliação do campo perceptivo, o que possibilitará o surgimento de novas ideias, como possíveis estratégias de atividades enquanto potência terapêutica ocupacional (FURTADO, 2010).

A relação terapêutica e de ensino pela escavação é uma relação horizontalizada onde terapeuta ocupacional e sujeito em tratamento ou em formação vivem as experiências sem se colocarem a priori uma hierarquia de saber. Na escavação, como método clínico, ao promover a desocultação do fazer, promove-se também uma circularidade da ação em que vários elementos se compóem e se interpóem; portanto, o espaço terapêutico é polifônico de saberes, de posturas, de amplitude, tanto espacial quanto temporal, e de circularidades (FURTADO, 2010).

As açôes do processo da escavação promovem o engajamento dele com as atividades através da abordagem do questionamento, da abordagem perceptiva, da indicaçáo da atividade e da análise da atividade. Essa autonomia na realização das açóes do processo da escavação em conjunto com o terapeuta ocupacional estabelece um processo de nutrição, sustentação, fortalecimento, autorização, acomodação e sacralização da vivência em busca da atividade sagrada (FURTADO, 2010).

Heidegger (2008, p. 225) faz uma explicação da hermenêutica como o ato criativo de elaborar um poema. Ele diz que todo grande poeta fala a partir de um único poema circundante, que é dito. A tarefa do diálogo pensante com o poeta terá de ser a de encontrar o lugar no ser que seja o fundamento do poema. "Só a partir do lugar que ocupa o poema (não dito) é que o poema individual brilha e ecoa." Para nós, a sacralização da atividade permite-nos levar os sujeitos ao "fundamento do poema" e afirmarem-se na experiência.

Essa é a explicação teórica da busca humana pela atividade sagrada cuja escavação, como método possível de ensino e terapêutico, promove no ser, por meio da desocultaçáo e dos desvelamentos, ao mesmo tempo que dá lugar a esse ser-atividade. Quanto mais escavo, mais redes, mais dispositivos e mais relaçóes promovo, e é essa busca do desvelamento do fazer que, a nosso ver, promove sentido à existência. Sentido na perspectiva de um horizonte, como nos diz Sardi (2003), daquilo que vai fazer com que o sujeito se mobilize, se identifique, se produza, se manifeste e se "cure", e é essa busca que possibilitará que um processo ocupacional garanta a presença (Dasein), a linguagem do ser.

Para Heidegger (2008) Dasein é uma palavra indicativa, indicativa de experiência, em que a possibilidade de compreender não é a de agarrar a realidade com esquemas já dados, mas sim a de deixar-se tomar pelo que faz a compreensão buscar compreender. Para o autor, a palavra é fonte de sentido e não portadora ou continente do já sabido. Portanto, traduzir ou compreender é a relação entre pensamento e linguagem enquanto pensamento e palavra a partir da experiência (HEIDEGGER, 2008). No processo de tratamento e de uma possível forma de ensinar Terapia Ocupacional, pelo Método da Escavação, o uso frequente da atividade revela no vivido da experiência o processo de traduzir e compreender o circundante, e com isso sacraliza-se o ato.

O poeta Rainer Maria Rilke (2006) nos diz que devemos amar a pergunta antes mesmo de obtermos a resposta, pois ao amarmos a pergunta a resposta emerge no momento certo e é consequência do quanto de amor colocamos na pergunta. Baseadas nesse pensar de Rilke foi que nos autorizamos a investigar o perguntar com amor a partir de como uma atividade nos envolvia e experimentar colocar amor nas perguntas. Dessa maneira, fui ensinando aos alunos e sujeitos em tratamento a formularem questóes que os ajudassem a obter, inicialmente, suas próprias respostas, tendo a atividade, o professor $\mathrm{e}$ o terapeuta como um interlocutor no processo de se perguntar. Para reforçar a explicação do ato de perguntar, faço uma citaçáo do autor:

[...] peço-lhe que tente ter amor pelas próprias perguntas, como quartos fechados e como livros escritos em uma língua estrangeira. Não investigue agora as respostas que não lhe podem ser dadas, porque não poderia vivê-las. 
E é disso que se trata, de viver tudo. Viva agora as perguntas. Talvez passe, gradativamente, em um belo dia, sem perceber, a viver as respostas (RILKE, 2006, p. 43).

A autora principal deste artigo foi influenciada por esse entendimento do ato de perguntar, com amorosidade, sentindo-se instigada a experimentar, ensinar aos discentes e também aos sujeitos em tratamento a viverem a relação com a atividade e pela atividade como uma grande pergunta que estariam fazendo a si, com toda a amorosidade de que fossem capazes.

O humano como obra de arte é um acontecimento em que a verdade, pela escavação, se revela e se faz representar pela captação da tensão criativa do escavar a atividade, dando forma a ela, escavando-a para escavar-se através dela, sacralizando o ato na experiência viva. Assim, traz para o domínio do ser, como sendo um todo, e abre ao homem essa luta interna, mundo espiritual versus mundo material, entre a terra e a transcendência, justificando a existência.

Arendt (1995) diz que se deve começar a pensar como se ninguém tivesse pensado antes e só depois começar a aprender com todos os demais, mas um pensar por nós mesmos. Essa fala de Arendt reforça o que a autora principal desse texto visualiza de potência no processo pedagógico e terapêutico de ensinar e tratar na Terapia Ocupacional através da escavação.

Sabemos, entretanto, que essa é uma questão filosófica que estamos pondo em discussão entre o conjunto dos nossos colegas, mas sabemos também que uma questão filosófica, mesmo sendo uma questão pontual, também estabelece redes, conecta-se a outras questóes, tecendo um campo mais amplo de investigação. Porém, não vemos isso como um problema, mesmo porque na Terapia Ocupacional o nosso saber também é articulado muito fortemente a outros saberes. Vemos, sim, como mais uma estratégia de sobrevivência profissional, ao levantar uma questão socrática sobre a forma de ensinar e tratar em Terapia Ocupacional através de um processo escavatório. A tal processo, inclusive, a autora principal desse artigo submeteu-se enquanto docente e terapeuta com o objetivo de que seus pacientes e alunos pudessem compreender a Terapia Ocupacional tanto como método clínico quanto como método de ensino. Para isso foi realizado durante cinco anos um grupo de estudos sobre a atividade humana, como laboratório para a realização da tese de doutorado da autora principal deste artigo, o que lhe permitiu sacralizar o método.

\section{Estratégias e recursos terapêuticos na Escavação}

Os valores, percepçóes e atribuições sobre as atividades de trabalho, atividades de ensino, as atividades enquanto recurso terapêutico e as atividades experienciadas, produzidas pelos sujeitos na experiência vivida, estão à espera de um lugar. Esses saberes, valores, percepçóes e atribuiçóes sobre as atividades começam pela ressignificação do uso do corpo e das singularidades que essas atividades produzem nesse fazer histórico em que as "dramáticas do uso de si" se instalam como elementos impulsionadores da produção desses saberes, oportunizando novas combinaçóes, novos conhecimentos, abrindo novas possibilidades de ressignificação da sua vida de trabalho, não trabalho e/ou formação.

As "dramáticas do uso de si" são o resultado da negociação do uso de si. Segundo Schwartz (2007, p. 196-197): "Uso de si, mas com essa dualidade às vezes simples e ao mesmo tempo muito complicada, o uso de si 'por si' e 'pelos outros'”. E é precisamente porque há ao mesmo tempo esses dois momentos, ou essas duas polaridades do uso, que "[...] todo trabalho é problemático - problemático e frágil - e comporta um drama; quer dizer que alguma coisa acontece." (SCHWARTZ, 2007, p. 196-197). Pensamos náo ser só o trabalho problemático; o envolvimento com alguma atividade, seja ela cotidiana, de lazer e/ou de trabalho, pode se tornar um problema e por isso conhecer e entender essa dramática de si é fundamental para a preservação da nossa saúde.

Para Canguilhem (2006), o que caracteriza o estado de saúde é a possibilidade de o sujeito ultrapassar a norma que define o normal momentâneo, é a possibilidade de tolerar infraçóes à norma habitual e de instituir normas novas em situaçôes novas. Para o autor, nada acontece por acaso, e sim por acontecimentos, por isso."[...] o meio é infiel, sua infidelidade, diz o autor, é o seu devir, sua história." (CANGUILHEM, 2006, p. 149). Na escavação, essa infidelidade tem lugar, mas não como um problema e sim como algo que necessita ser escavado, acolhido com amorosidade, para que possa ocupar um lugar no corpo e na alma sem adoecimento.

Ainda sobre o conceito de saúde, o autor diz que é uma forma de olharmos a existência em uma perspectiva não de possuidor ou portador, mas, também, quando necessário, "de criador de valor e instaurador de normas vitais." (CANGUILHEM, 2006, p. 152). 
Com a análise da atividade que o terapeuta el ou professor faz em conjunto com o sujeito, essa nos possibilita a instauração de normas vitais e criação de valores. Ela é baseada nos elementos da percepção e naquilo que está sendo vivido na experiência do encontro. São sinais que o sujeito vai dando de como ele se envolve ou não se envolve com as coisas, ou de como ele se relaciona com elas; que tipo de investimento ele faz. Ela surge também de um saber anterior do terapeuta e/ou do professor e do sujeito, de pesquisas de atividades, pois esses, em sua trajetória de vida, experimentam muito as atividades em si próprios, no seu cotidiano, no seu trabalho, o que lhes permite indicar uma atividade.

A partir dessa indicação da atividade é que o Terapeuta Ocupacional e/ou professor dá início ao processo da escavação, com os questionamentos em cima daquilo que ele está fazendo naquele momento ao realizar a atividade. Paralelamente à execução dela, pelo sujeito, o terapeuta indica outras atividades para ele fazer em casa para que, nesse processo, o sujeito possa ir se percebendo. Quando retorna para o atendimento, é feita nova escavação da atividade realizada. Dessa forma, vai se ampliando o campo perceptivo, oportunizando a vivência do escavar-se. Explicando melhor essa indicação de atividade, é uma indicação negociada com o sujeito, a partir do campo perceptivo do terapeuta e/ou do professor, em que eles apontam o percurso de sua percepçáo e o processo de escolha da atividade. Nesse processo, tanto de ensino como clínico, a socialização dos saberes se encontra.

Isso significa avaliar o fazer cotidiano do outro, analisar a atividade realizada, analisar o náo fazer, avaliar a incapacidade, investigar a renormatização desse fazer e de que maneira ele foi produzido, o que gerou de singularidades nesse processo, investigar novas possibilidades desse fazer e quais os dispositivos que serão utilizados para produzir novas normatizaçôes que possam incluí-lo socialmente. Aqui, destacamos que na formação dos terapeutas ocupacionais esse fazer passa pelo desenvolvimento de atividades experienciadas e analisadas, desenvolvendo no aluno a capacidade de observação e de percepçáo.

A escavação do que ocorre no processo de realização $\mathrm{da}$ atividade, por meio dos questionamentos, faz emergir o modo como o sujeito a realiza, como se sente fazendo, como se sente frente aos materiais, quais as sensaçôes ao desenvolvê-la, que lembranças emergem desse processo, que associaçóes ele produz ao realizá-la, como o seu corpo reage frente a ela, quais as perguntas que estáo emergindo tanto para o terapeuta como para o sujeito. É ir realmente escarafunchando o sujeito pela atividade, mas isso sempre na perspectiva de produzir um encontro de si para consigo, de si para com o outro, de si para com a própria atividade e da atividade e do material para com ele.

Outro aspecto importante a destacar no processo da escavação é que o resultado do processo daquilo que é vivido na experiência não dá margem para o fracasso e/ou erro, porque a atividade no processo da escavaçáo se refaz todo o tempo, e o acolhimento amoroso das perguntas impede ou dilui o julgamento do feito e valoriza o processo.

Ao longo do tempo, o terapeuta e/ou professor vai avaliando a maneira como o sujeito vai lidando com o processo da escavação, o tipo de reaçáo que ele vai tendo, a forma como ele vai se comportando corporalmente, todas as manifestaçôes físicas, mentais e/ou emocionais. No processo da escavação, o terapeuta e/ou professor vai mostrando pra o sujeito o que está se modificado no processo, checando a percepção dele, a partir da indicação acordada da atividade e da forma como ele está lidando com tudo. Aqui, a confrontação e a autoconfrontaçáo pela atividade acontece.

Às vezes, é necessário mostrar ao sujeito exatamente como está operando-se naquele momento, no presente, a relação dele com a atividade. Também é necessário às vezes recapitular e vivenciar novamente aquela atividade a fim de que aquilo que emergiu e foi percebido pelo terapeuta e/ou professor, mas ainda não faz parte do campo perceptivo do sujeito, possa ser vivenciado novamente, ampliando seu campo perceptivo.

Aqui, o terapeuta se utiliza de um princípio gestaltiano de viver o "aqui e o agora" na experiência. Nesse processo, é importante entender, conhecer e ter uma percepção real do sujeito para que o terapeuta e/ou professor busque em que bloco de atividades ele se encaixaria, se pela via das atividades estruturadas, atividades livres, se pelo caminho das atividades expressivas, socializantes, intelectuais, cognitivas etc.

Nesse momento, o saber técnico da Terapia Ocupacional é acionado pela classificação geral das atividades em Terapia Ocupacional, e isso o terapeuta e/ou professor faz a partir dos questionamentos durante a escavaçáo. Com isso, vai entendendo melhor o funcionamento do sujeito, checando aspectos de sua história de vida para, a partir desses dados, ampliar o campo de atividades a serem escavadas. Nessa relação de cumplicidade que constrói-se nesse fazer compartilhado, o sujeito vai perceber-se na atividade produzindo o autoconhecimento, sendo papel do terapeuta e/ou professor auxiliá-lo nesse processo. 
Ao realizar as atividades (experiência e o saber como experiência) por meio do processo da escavaçáo (questionamento do vivido no aqui e no agora da experiência e pelas memórias e percepçóes que essa experiência e a escavação promovem), o sujeito em tratamento vai viver a consciência de si e o cuidado consigo próprio, cuidado esse no sentido de uma epimeleia, como nos diz Foucault (1985), mas tendo o terapeuta ocupacional como mediador da relação entre a atividade, a experiência e a escavação no sentido da produção de vida. Então, a atividade, a ocupação e/ou a tarefa são como um meio e também um fim; o aprendizado é escavar-se, pois ao fazê-lo acessa-se o sagrado em si.

Ao fazer isso, o terapeuta ensina o sujeito a perguntar e ao mesmo tempo a desvelar o campo perceptivo da sua experiência em tratamento, produzindo um novo olhar sobre a experiência vivida. Isso acontece acoplado ao conhecimento ou ao aporte teórico prévio da formação tradicional do terapeuta ocupacional e do conhecimento prévio do sujeito. Ao prover novos agenciamentos e dispositivos de saber ao aluno, ao sujeito em tratamento, potencializando sua formação e criando novas demandas de investigação desse saber através de novas experiências e da ampliação da percepção, possibilita-se o surgimento de novas ideias como possíveis estratégias de atividades enquanto recurso terapêutico.

A partir do exposto, nomeamos, ainda sem um caráter definitivo, como operar o processo da escavação e alguns passos que, embora requeiram outros estudos, consideramos importantes para a sua realização como método clínico.

Como primeiro ponto, devemos produzir a identificação do sujeito. Nesse processo, já iniciaremos a sondagem das várias possibilidades de iniciarmos o processo da escavação e, em seguida, avaliamos as condiçôes para que ela aconteça. Essa avaliação requer uma inter-relação com todo o processo de tratamento do sujeito, as várias interlocuções entre os profissionais, familiares, comunidade e, principalmente, com o próprio sujeito.

É importante também que o próprio terapeuta possa avaliar as condições físicas, mentais, psíquicas e sociais do sujeito para que a escavaçáo inicial tenha êxito. Principalmente, colher do sujeito o desejo de se fazer perguntas. Após esse processo, é feito em conjunto com o sujeito um levantamento do material que será utilizado no processo e quais as possíveis atividades, definidas pelo sujeito ou sugeridas pelo terapeuta, para serem elaboradas.
O próximo passo é discutir com o sujeito o tratamento que vai ser dado ao material que emerge da escavaçáo, tanto do ponto de vista do que foi dito como também do que foi feito. Nesse momento é fundamental dar um lugar, acomodando o material que emergiu do processo, pois a continuidade da escavação depende desse cuidado com o material e com o sujeito. $\mathrm{O}$ passo seguinte é a finalização da atividade e a busca de novos elementos para serem escavados, surgidos ou náo pelo processo anterior. Como finalização, é acordada com o sujeito a elaboração de um relatório cuja criação é de responsabilidade do sujeito. $\mathrm{O}$ terapeuta também produz um relatório que pode, em futuras escavaçôes, ser confrontado com o anterior, dependendo da situação. Esse relatório é uma descrição do processo, que pode ser construída na forma escrita ou verbal.

$\mathrm{O}$ envolver-se em uma atividade permite confrontar os questionamentos, as lembranças, as histórias, os acontecimentos, as dificuldades cognitivas de desempenho, as operaçóes na execução $\mathrm{da}$ atividade e as escolhas. $\mathrm{O}$ terapeuta e/ou professor é o mediador do processo de ressignificação e de renormatização do fazer pela atividade e ele está todo o tempo produzindo observaçóes e percepçóes, devendo checá-las.

$\mathrm{Na}$ verdade, a grande questão é que o processo da escavação não o é só para o sujeito em tratamento; ele o é também para o terapeuta e/ou professor, pois a todo o instante em que esse escava o sujeito, também está escavando a sua própria intervenção com ele. Por exemplo, ao se dar conta de que determinada pergunta náo teve sentido, de que não poderá ir por determinado caminho, entáo, ao mesmo tempo em que faz as observaçôes, tem que checá-las. O terapeuta e/ou professor nesse processo não tem a verdade; ela é produzida na experiência, pelo conhecimento de si e do próprio sujeito e pelos questionamentos.

A confrontação daquilo que se observa com aquilo que se faz tem de estar sempre presente. Em todo o processo, terapeuta e sujeito em tratamento, professor e aluno, na ação pedagógica, estão confrontando seus saberes.

A indicação de uma determinada atividade se esgota para o terapeuta quando ele náo tem mais elementos para escavar, formular novas perguntas. Entretanto, ela pode não se esgotar para o sujeito, que pode seguir fazendo; porém, o terapeuta sugere que ele a realize em outro momento. A intenção do terapeuta é cada vez mais ampliar o processo de questionamento, pela escavaçáo de uma atividade, pois é dessa forma que o sujeito ganha potência para renormatizar, ressignificar o seu fazer pela 
consciência de si e aproximar-se cada vez mais do caminho para a sacralização da atividade.

\section{A sacralização da atividade}

De acordo com Schwartz (2003), toda a atividade de trabalho encontra saberes acumulados nos instrumentos, nas técnicas, nos dispositivos e é, portanto, saturada de normas de vida e formas de exploração da natureza e dos homens. Schwartz (2003) entende "norma", baseado no conceito de Canguilhem (2006), como sendo

[...] um modo possível de unificar um diverso, de reabsorver uma diferença, de resolver uma desavença. Norma é aquilo que fixa o normal a partir de uma decisão normativa. (CANGUILHEM, 2006, p. 207).

A busca da atividade sagrada é um processo permanente de escavação e uma decisão normativa, em que o sujeito vai estar na atividade e vai vivê-la por inteiro, genuinamente, sem mascaramentos; é a entrega do sujeito à atividade, para com o outro, para com ele mesmo e nele mesmo. A sacralização do feito é desenvolvida pelo movimento contínuo de reverência à atividade, pela escavação, o que permite ao sujeito estar na presença (Dasein). Isso é indizível, mas possibilita o sujeito ao vivido e o remete a uma nova busca a partir do que emerge no movimento da sacralização do feito, proporcionando-lhe saúde. A esse acontecimento denominamos atividade sagrada, atividade essa repleta de poder e significação, possibilitando ao sujeito Ser.

A significação não é algo que o homem dê a um objeto; é, ao contrário, algo que o objeto dá ao homem, fornecendo-lhe a possibilidade das palavras e da linguagem. Heidegger (2008) diz:

É a partir da significância aberta, no compreender de mundo que o ser da ocupação, com o manual, se dá a compreender, qualquer que seja a conjuntura que possa estabelecer com o que the vem ao encontro. (HEIDEGGER, 2008, p. 209).

A significação é algo que se funda sobre algo anterior à linguagem, pois essa já é uma maneira de ver, um modo elaborado de ideaçáo. A compreensão e a significação conjuntamente constituem-se a base da linguagem e da interpretação. As coisas ganham status de ser e de existir a partir das palavras e da linguagem. Sobre isso, Heidegger (2008) nos fala:

A fala é a articulação significativa da compreensibilidade do ser no mundo, a que pertence o ser com, e que já sempre se mantém num determinado modo de convivência ocupacional. (HEIDEGGER, 2008, p. 224).

Para o autor, o ser da cura é o ser junto como ocupaçáo e o ser como copresença dos outros, nos encontros dentro do mundo, que ele designa de preocupação. $\mathrm{O}$ ser junto-a é ocupação, porque é o modo de ser-em. Para o autor, a cura não é uma atitude isolada do eu para consigo mesmo, porque ela já se caracteriza ontologicamente como anteceder-se a si mesma, o que já nos colocaria na condição dos dois momentos estruturais da cura: ocupação e preocupação. Ela é uma atitude da presença para a apreensão explícita da totalidade originária da presença e aí o ser desvela-se como cura (HEIDEGGER, 2008).

A forma como entendemos a intervenção terapêutica ocupacional encontra uma correspondência nessa maneira de interpretar a cura e entender os "dois momentos estruturais" dela, preconizados pelo autor, como base para o entendimento do papel da ocupação, sendo esse estruturador da vida cotidiana e da presença do Ser.

Enquanto totalidade originária, a cura se acha, do ponto de vista existencial, "antes" de toda atitude e situação fática da Presença. Esse "antes" para mim é o questionamento. Portanto, o querer, o desejar, a tendência e a propensão são fenômenos que só podem ser descritos a partir de uma redução ontológica da presença. $\mathrm{O}$ existir fático da presença não está no poder ser no mundo, mas já está sempre empenhado no mundo das ocupaçôes. O que o sujeito precisa é ter a compreensão de como isso se processa em si. Teoria e prática são possibilidades ontológicas de um ente cujo ser deve determinar-se como cura (HEIDEGGER, 2008).

A ocupação é entendida pelo autor como "[...] uma circunvisão que se funda na temporalidade e no modo de uma atualização que aguarda e retém." Nas ocupações em que planeja, providencia e previne sempre; já se diz de maneira perceptível ou não:

[...] isso deve acontecer, disso se conclui, vai se recuperar". Portanto, é no aguardo que as ocupaçóes se pronunciam; é retendo que ela se pronuncia no entâo ou outrora, e é atualizando que o faz no agora (HEIDEGGER, 2008, p. 501).

$\mathrm{Na}$ circularidade das relaçóes, promovidas pelo processo da escavação, esse "aguardo" é desvelado naquilo que é pronunciado, retido e atualizado no ato de realização de uma ação-escavação.

Decisivo no dimensionamento do Dasein como cura é esse, para além, antecipador da presença, 
esse si mesmo, experienciado como alteridade. Para o autor, a cura é aquilo com o qual "[...] me preocupo e me dedico[...]” (HEIDEGGER, 2008, p. 267). Na abordagem do questionamento (Método da Escavação), esses elementos se justapóem, possibilitando a ação sacralizadora do feito, o que deverá permitir ao sujeito relacionar-se com amorosidade e, portanto, curar-se.

\section{Referências}

ARENDT, H. A vida do espirito. Rio de Janeiro: Relume; Dumará, 1995.

CANGUILHEM, G. O normal e o patológico. 6. ed. Rio de Janeiro: Forense Universitária, 2006.

CLOT, Y. A função psicológica do trabalho. Petrópolis: Vozes, 2006.

CUNHA, D. M. Notas conceituais sobre atividade e corpo-si na abordagem ergológica do trabalho. In: SEMINÁRIO NACIONAL DE EDUCAÇĀO PROFISSIONAL E TECNOLOGIA - SENEPT, 1., 2008, Belo Horizonte. Anais eletrônicos.... Disponível em: <www. senept.cefetmg.br>. Acesso em: 29 set. 2008.

FERREIRA, A. B. H. Novo dicionário da lingua portuguesa. 2. ed. Rio de Janeiro: Editora Nova Fronteira, 1986.

FREIRE, P. Pedagogia do oprimido. Rio de Janeiro: Paz e Terra, 2005.

FURTADO, E. M. A. Método da escavação como recurso de ensino e clínico em terapia ocupacional na perspectiva ergológica. 2010. 477 f. Tese (Doutorado em
Educação)-Universidade do Vale do Rio dos Sinos, São Leopoldo, 2010.

FOUCAULT, M. História da sexualidade 3: O cuidado de si. Traduçáo de Maria Theresa da Costa Albuquerque. Rio de Janeiro: Graal, 1985.

FOUCAULT, M. Microfísica do poder. 7. ed. Rio de janeiro: Graal, 1988.

HEIDEGGER, M. Ser e tempo. Petrópolis: Vozes, 2008. JOSSO, M. Experiências de vida e formação. São Paulo: Cortez, 2004.

MEDEIROS, M. H. R. Terapia ocupacional, um enfoque epistemológico e social. São Paulo: Hucitec, 2003.

QUARENTEI, M. S. Terapia Ocupacional e produção de vida. In: CONGRESSO BRASILEIRO DE TERAPIA OCUPACIONAL, 7., 2001, Porto Alegre. Anais... Porto Alegre: ABRATO, 2001. CD-ROM.

RILKE, R. M. Cartas a um jovem poeta. Traduçáo de Pedro Süssekind. Porto alegre: L\&PM, 2006.

SANT’ANA, D. (Org.). Políticas do corpo. Sáo Paulo: Estação Liberdade, 1995.

SARDI, S. A. Viver e pensar. In: QUEIROZ, I. P. (Org). Filosofia e ensino - possibilidades e desafios. Ijuí: Unijuí, 2003. p. 167-189.

SCHWARTZ, Y. (Org.). Trabalho e ergologia: conversas sobre a atividade humana. Niterói: Universidade Federal Fluminense - EdUFF, 2007

SCHWARTZ, Y. Trabalho e gestão: níveis, critérios, instâncias. In: FIGUEREDO, M. et al. (Orgs). Labirintos do trabalho. Rio de Janeiro: DP\&A, 2004. p. 23-36.

SCHWARTZ, Y. Trabalho e saber. Trabalho e Educação, Belo Horizonte, v. 12, n. 1, p. 21-34, jan./jun. 2003.

\section{Contribuição dos Autores}

Eliana Anjos Furtado: autora principal do artigo. Juliana Leitão Marcondes: colaborou com as reflexôes e a redação. Ambas as autoras aprovaram a versão final do texto. 